\title{
Experimentation of a new pedagogical method in first year's teachings of physics
}

\author{
Jean-Marc Virey* \\ Aix Marseille Université, Centre de Physique Théorique, Marseille, France \\ E-mail: Jean-Marc.Vireyeuniv-amu.fr
}

\begin{abstract}
The teaching of physics for first year post-bac students is confronted to increasing difficulties since several years. This problem is reinforced this year in France due to a new reform of the secondary educational system. We have experienced a new pedagogical method in the cursus "préparation aux écoles d'ingénieurs Polytech", which is the first year of the Polytech engineer school of the Aix Marseille University.

The pedagogical method is a mixing between "problem based learning" and "peer instruction". The results of the method are very encouraging.
\end{abstract}

The outline of this talk is the following :

- listing of problems encountered by students and teachers

- presentation of the new pedagogical method

- results of the first year's experimentation

Frontiers of Fundamental Physics 14 - FFP14,

15-18 July 2014

Aix Marseille University (AMU) Saint-Charles Campus, Marseille

\footnotetext{
* Speaker.
} 


\section{Problems for students and teachers}

When students arrive for the first time at university they are confronted to many difficulties, and their teachers too. Some problems are so contradictory that they can get the status of paradoxes. The learning is strongly impacted by these difficulties and this is the role of the teachers and of the institution to reduce them. The aim of this first section is to give a look at these paradoxes.

The origin of the difficulties has many sources intimately correlated. The transition between high school and university is one of them. This passage is strongly dependent on the country under consideration, and we are concerned here by the French educational system. The main problem is linked to a different vision of the learning goals for both institutions. This difference is critical in the fields of physics and mathematics on which we focus on.

The magnitude of the problem depend on which formation at university we are talking about. In France, there are several types of formations where physics and mathematics (and chemistry) are preponderant. Usually, the best students attend a postsecondary system, called "classes préparatoires" (CP), in order to enter an engineer school two years later. The students are selected on their grades in high school, they should have an average mark of 14/20 over the last high school year. Even these students face strong difficulties with physics. In undergraduate formation at university ("Licence") where no selection is made, the situation is worse. In the following we present the experimentation of a new pedagogical method in the CP system "préparation aux écoles d'ingénieurs Polytech" (PEIP), the first year of the Polytech engineer school of the Aix Marseille University.

\section{- The student paradox}

Most of the students beginning a physics' formation are not aware of what it means. They have, usually, a large ambition in the sense they want to become engineer or researcher but have no idea of the amount of work required for that. Their working methods and abilities are very far from the exigence required at university. Being eighteen year's old, leaving for the first time their parents' house and hence the parental control, they have so many external solicitations that they imagine they can pursue high level studies with a maximal minimisation of time! After few weeks, they begin to understand what is demanded and hence, for most of them, they realise that their motivation is opposed to their expectations... This is the "student paradox".

A teacher, practising since several years at university and talking about present students, will now make a pessimistic list of problems like this one : knowledge is wider but far more superficial, technical abilities to perform mathematical calculus and physical reasoning is almost non-existent, experimental abilities is rather low, working methods are not adapted (memorisation instead of understanding) and maturity is lower than at primary school when they had the age of reason !

Of course, students are not fully responsible of these facts which come from the educational system itself and from society's evolution. We have to adapt the university system by transforming the curriculum, our teachings and the learning methods.

\section{- The French secondary educational system reform}

A deep reform has been applied to the secondary system recently. The newly shaped students arrived at the university's gates in 2013. We mention the main changes only. In fact, most of the problems listed above have been reinforced by the reform. In particular, formation in physics has been replaced by scientific culture. For instance, the bachelor (bac) exam in physics is almost 
now a text explanation instead of exercises resolution. The approach is more important than the contents ${ }^{1}$. Calculus ability is strongly decreased. For instance, the program of mathematics gives now an important part to statistics and probabilities to the detriment of derivation and integration of usual functions, vectors calculus and complex numbers understanding.

However, the reform has some important advantages. Besides a wider and a more practical knowledge, the same subject is reached by different pedagogical methods. Before the reform, the teachings were mainly theoretical with few practices in experimental environments, and exams were based on exercises resolution. Now, experimentation is reinforced and many subjects are studied through projects and training courses where the scientific approach is enlightened. In fact, the real benefit of the reform is that students are now ready for active learning !

\section{- The teacher/system paradox}

The teachers are confronted to another paradox coming from the slow evolution of the educational system. Since more than twenty years, one assists, either in secondary school or in the first year at university, to the increase of the contents of the official programs and to the multiplication of the pedagogical methods used to study a particular subject. On the other hand, time allowed for physics instruction has decreased. This is the reason why one may consider that students have a wider but more superficial instruction than previously. The paradox arises when we realise that no adaptation of the programs have been made at university beyond the first year. Indeed, since fifteen years the first year contents have changed several times, but almost nothing has changed for the second year and even less at the level of the master degree.

The most problematic example concern mechanics' teaching. To make space for new teachings like epistemology, English and French, or for new approaches like project based learning and to increase experimental manipulation, the amount of time allowed for mechanics has been divided by three in twenty years. Is it bad? Not necessarily. The damage comes from the fact that the program has not been changed, the prerequisite for the second year neither. Twenty years ago mechanics was already the big piece for students, now with reduced allowed time, identical program and a less adapted formation at high school we can easily understand the students and teachers' despair involved in these courses !

Consequently, we arrive naturally at the awful situation where programs are very ambitious and in complete contradiction with the acquired knowledge of students having their successful exams in the pocket. The absence of effort has no sanction. The voids are never filled up later on. The consequences are numerous. Students, being not stupid, realise the gap between lectures and ability requirements, and hence minimise their attention in lecture hall, if they come at all... Partial knowledge before beginning the study of a new field, put students in a very unwholesome situation and motivation decreases. Students are innocent in this story. University system is guilty and should realise a deep transformation to solve, at least partially, this strong paradox which is the main responsible of the failure of traditional education at university. An indirect consequence of this system paradox is to reinforce the heterogeneity among students.

\section{- Traditional education at university}

Traditionally in French universities the instruction is organised vertically. General lessons are

\footnotetext{
${ }^{1}$ This has some general virtues, indeed, but to the detriment of knowledge and abilities in physics...
} 
given in lecture hall where the teacher presents the knowledge on a particular field. Students are passive. Rarely, they go to the library to increase the understanding or to complete the teacher's course. In parallel, students follow recitation sections where exercises have to be solved under the guidance of an instructor. Solutions are given and detailed by the teacher at the end of the session.

This pedagogical method works quite well after the third year when students have a strong motivation. A critical look at the situation for first year students indicates that the best $5 \%$ only acquire the expected knowledge and problem solving abilities. For more than $90 \%$ of the students, time is purely and simply wasted! In lecture hall, most of the students sleep, discuss or play with their phones, if they come at all... They consider the lectures boring and useless to get their exams. In recitation sections, they don't use their brains before or during the session because solutions are given at the end. Most of them still consider that reading once the correction is enough for understanding. In both cases, the students are completely passive and teachers are boring too... Around $60-70 \%$ of the students fail the exams.

Consequently, teachers, fully aware or not of this major crisis, try to find various solutions. Most of them minimise their implication in their teachings in order to maximise their satisfaction in performing research. Usually, they "wear blinders" and teach for 5\% only. Conscientious teachers break down, or to avoid it, can stop teaching for another job... Most of my colleagues belong to one of these groups. I've wandered among these states of mind for years. Here, I want to point out that actual alternatives exist: Change your practice and make active learning !

\section{A "new" pedagogical method for active learning}

Active learning may be realised in practice through many different ways. Well-known methods are, for example, peer-instruction [1,2] and project or problem based learning [3]. The main point of these approaches is to put students at the center of the learning process. Teachers are transformed into tutors following the Milgrom's guideline [4] : "less teaching yields better learning !" Of course, each method has its own peculiarities, and large variations for practical application exist even within the same label. Being a non-specialist I will not discuss the virtues and problems of each method. In the following, I discuss a "new" method based on a mixing of peer instruction and problem based learning. Nothing is "new", certainly one can find many other places in the world using a similar method. In fact, "new" qualifies merely the feelings of the teachers who shared with me the experimentation of a particular form of active learning in the first year of PEIP. After many readings and discussions we have converged towards the method presented here.

\subsection{Framework}

The main objective of the method described below is to develop a deep understanding of the discipline through physics thinking and problem solving abilities. Namely, it concerns the learning of the theoretical aspects of physics used to describe physical phenomena (approximations, model constructions, laws, theories, mathematical tools...). This part of physics raises the most severe problems today. Of course, in parallel to theory's learning, around one fifth of the time is devoted to experimental practice, either to develop intuition for specific phenomena or to synthesize all the knowledge of the semester in some more complex experiments. We don't discuss these experimental aspects in the following. 
We applied the method to the whole 2013-2014 (and 2014-2015 too) PEIP promotion, corresponding to 140 students decomposed into 5 classes of 28 students. We recall that students are selected with at least the mention "good" at the bac and an average notation of 14/20 in high school. The teaching units concerned are mechanics ( 3 hour/week, whole year), geometrical optics ( $2 \mathrm{~h} / \mathrm{w}$, first semester) and electricity $(2 \mathrm{~h} / \mathrm{w}$, second semester).

\subsection{Principles}

\section{- No lecture}

Since the presentation of the course in lecture hall is totally inefficient, there is no lecture at all ! Students should work on books at home individually. Before each session (ie "tutorial") the teacher gives a clear plan of the studies to be performed. We expect around 3 hours of homework to prepare a session of 2 hours. The first reference book [5], very pedagogical and rather easy, provide simple introductions and application exercises. The reading is optional but strongly recommended. The second and principal documents, handouts in optics and electricity, a book for mechanics especially written for the pedagogical method [6], contains all the elements of the official programs. Applications and fundamental aspects of the new ideas are introduced with a pragmatic and/or historical point of view. An initiation to solving physics problem is given through "course exercises" with extremely detailed solutions.

\section{- No exercise correction and work in group}

The teacher meets students in classroom during tutorials only. Students should resolve few exercises or a big problem during this time. The teacher does not provide any correction except for the most difficult questions. At the beginning of the tutorial, if requested by the students, course recall of the essential points may be given. The work is organised in 4 teams of 7 students in a collaborative way with a precise timetable to be respected. Each student should participate to the discussions and has a main role : leader, scribe, secretary, timekeeper, numerical performer, result evaluator... (more details in [3]). The teacher is a simple tutor who answers questions by questions and is a guide towards the good way. The best tutorials are the ones where the tutor does not say anything in 2 hours work ! It happens 2 or 3 times in a semester of 29 tutorials...

Working in group is an essential ingredient of the method, and more details can be found in [3].

$\rightarrow$ Individual learning of the discipline is promoted through collaboration :

better preparation of the understanding, confrontation of different point of views, emulation among students within the group, student auto-regulation, and last but not least, the basis of peer instruction [1], the necessity to explain own ideas and to communicate to others.

$\rightarrow$ General abilities, beyond physics, are developed :

critical reasoning, logical and analytical approaches of the problem, decision taking, auto-evaluation, communication, conflict resolution...

\section{- High frequency evaluation}

Without frequent evaluation, students don't work at all. 5\% only have enough maturity to study without pressure, it's a pity for them but essential for the others. Examinations take several different forms :

- Each tutorial begin with a 10-15' evaluation of the homework. When studying a new chapter, we give a quiz in order to see if definitions are known and easy application exercises are understood. 
We use clickers to have a quick estimation of the results, allowing for immediate course recalls if necessary.

- We replace the quiz by a small paper examination when fundamental course exercises should be studied deeply. Students are informed and, sometimes, the subject is even given in advance! (For instance, this is the case when studying polar coordinates and general circular motion).

- Each student should write a report of the previous tutorial, where the correction of each exercise, found within the team, should be written properly. The teacher takes randomly $1 / 3$ of the reports for evaluation.

- When time permits, we perform oral examinations. Best students can make course recall at the beginning of the tutorial instead of the teacher. Weak students present the results of the team at the end of the tutorial but the mark is for the whole group ! Emulation and peer instruction are reinforced, however it takes a long time to do it...

- There are 2 partial exams of $1 \mathrm{~h} 30$ and a final exam of $3 \mathrm{~h}$. The teacher gives also a general mark, equivalent in weight to a partial exam, which takes into account all the tutorial evaluations.

\section{Results}

\section{- Rate of students with solid knowledge and abilities increase}

In spite of a lower initial level for calculations and for solving problems, due to the secondary school reform, and with more difficult examinations (see below), we succeed in driving higher much more students. With traditional teachings we were satisfied by $5-10 \%$ of the students. With the active learning method described above we reach a rate of $30-60 \%$ (the range is big due to strongly varying team emulation within a class). This general feeling is confirmed by the final score examination which increases from 7-8/20 up to 9-10/20 (average). The high rank students get even better results, from 12-14/20 they reach now 16-19/20.

\section{- Increase of exams difficulty and program}

At the end of the semesters we have been able to propose more difficult exams. Instead of classical exercises we've given synthesis problems like 10 years ago and we got better results! In addition, with the same allowed time we have been able to enlarge the program studied, a step towards the reduction of the teacher/system paradox mentioned above.

\section{- Positive evaluation and collaborative works}

Others indicators show the relevance of the active learning strategy. First, the evaluation of the pedagogical method by the students is clearly positive : $58 \%$ find the method efficient at the end of the first semester, and this number increases to $72 \%$ at the end of the second semester. Surprised at the beginning by the work in team and by the absence of course, they find the virtues of the pedagogy through practice. This feeling is confirmed by tutors who see the emulation among students increasing with time. We have even seen, for the best teams, the students wanting to work together, in the same way, in other disciplines! The best students said, with happiness and pride: "For the fist time we've worked harder in physics than in mathematics". The year after, these students asked us "Why don't we always work in team in other classes?"

\section{- Difficulties}

- Students need at least 1 month to understand the necessity to work (hard) and that requirements 
are far more important than at high school. For instance, the major began with $4 / 20$ at the first partial exam to end with $18,5 / 20$ at the final exam of the second semester...

- Team emulation works well if more than 4 students (among 7) play the game. 1 or 2 groups (among 4) per class had a weak emulation. There are surly/contrary students (10-20\%) either because they have many difficulties (future failed students) or because they hate physics even if they are good in others disciplines. This last category is the worse case, students with this mentality are difficult to manage and push downwards the other students of the team.

- Pressure should be permanent to maintain the high level of work. Indeed, if the teacher relax pressure, or if students get high marks during partial examinations, they stop working ! Maturity needs time to come...

- Tutor/teacher should be convinced of the relevance of the method and involved during tutorial, otherwise student's motivation decrease and difficulties increase.

\section{Conclusion and teacher pleasure}

This pedagogical method allows to reduce considerably the student paradox. Indeed, students have a clear contract : if they are passive failure is guaranteed. They are pushed to be active and to take control of their own learning. Moreover, they learn to work collaboratively into teams which develop additional skills. It seems clear that students are the first beneficiaries of this pedagogical method. When the motivation is mitigated, active learning is more powerful than classical teachings. Nevertheless, in this conclusion, I want to insist on the fact that there are second beneficiaries of the method : the teachers !

It's hard for a teacher to become a tutor. In lecture hall, we are pride to expose our knowledge obtained after so many efforts, but we should be aware not to be overwhelmed by our ego... Courses in lecture hall are not efficient any more, and the despair is enormous when teaching to zombies. When we see the students discussing among themselves about physics, exchanging ideas, developing critical reasoning, and the ones explaining to the others as a teacher, it's a real pleasure. The frame of the method obliges the students to do it, and it happens 5 minutes after the beginning of the first work in teams !! All my colleagues and me, with our tutor costume, are happy to go in classes, and now, it seems difficult for us to "teach" differently.

\section{References}

[1] E. Mazur, Peer Instruction: A User's Manual, Upper Saddle River, Prentice-Hall (1997). See also, A. L. Rudolph et al., Phys. Rev. Special Topics - Phys. Educ. Research 10, 010103 (2014).

[2] N. Lasry, Pédagogie collégiale, vol. 21 n 4 (2008).

[3] E. Milgrom et al., Guide pratique pour une pédagogie active : les APP, http://enseignants.insa-toulouse.fr/fr/l_app/le_guide_app.html

[4] E. Milgrom, proceedings of this FFP14 conference, physics education session.

[5] H.D. Young and R.A. Freedman, University Physics, Pearson (2013).

[6] J.-M. Virey, "Physique et mécanique, une initiation à la résolution des problèmes de physique", Presse Universitaire de Provence (2015), to appear. A shortened electronic version can be found there : http://www.cpt.univ-mrs.fr/ virey/ 